\title{
Forest climatology: reconstruction of mean climatological data for Bavaria, Germany
}

\author{
Youlong Xia*, Peter Fabian, Andreas Stohl, Martin Winterhalter \\ Lehrstuhl für Bioklimatologie und Immissionsforschung, Ludwig-Maximilians-Universität München, \\ Am Hochanger 13, 85354 Freising, Germany
}

Received 25 September 1998; received in revised form 11 March 1999; accepted 23 March 1999

\begin{abstract}
A method is presented that allows the reconstruction of forest climatological data using data available from routine weather stations. Data from 32 routine weather stations were used to estimate the monthly mean values of daily mean air temperature, daily maximum temperature, daily minimum temperature, water vapour pressure, wind speed and precipitation at eight forest climate stations in Bavaria. The data obtained at these stations were used to establish empirical transfer functions to transform data interpolated from the weather stations to values that are valid for the different meteorological conditions in the forests. These empirical transfer functions between observed and interpolated climatological data are derived using a universal regression technique. The results show that using empirical transfer functions reduced the mean absolute errors between observed and estimated monthly mean climatological data significantly as compared to simple interpolation. A 31 year (19651995) monthly mean forest climatological data set in Bavaria, reconstructed using Barnes interpolation and the empirical transfer functions, was used to compare the forest microclimate with the surrounding mesoclimate. In addition, the climates of three typical forest regions were compared. (C) 1999 Elsevier Science B.V. All rights reserved.
\end{abstract}

Keywords: Empirical transfer functions; Reconstruction; Weather stations; Forest climate stations

\section{Introduction}

Climatological data at forest sites are important for studying the photosynthesis and forest growth, monitoring forest ecology, simulation of evapotranspiration and forest water cycle, and forest damage. But the available forest climatological data are sparse, especially for long-term climatological studies. As an alternative, climatological data from weather stations were often used in forest studies (Running et al., 1987;

\footnotetext{
*Corresponding auhtor. Fax: +49-81-6171-4753

E-mail: xia@arbwiss.arwi.forst.uni-muenchen.de (Y. Xia)
}

Russo et al., 1993; Bolstad et al., 1997, 1998). A method often used is to interpolate the climatological data of weather stations to forest sites (Hendriks et al., $1997 \mathrm{a}, \mathrm{b})$ or to use the climatological data of the closest weather station. However, the estimated forest climatological data obtained in this way are usually not accurate (Hendriks et al., 1997a, b), because most weather stations are located in suburbs, valleys and rural areas distant from and not representative for the meteorological conditions in the forests.

In order to investigate the possible effects of climate anomalies on forests, the Bavarian State Institute of Forestry has installed 22 forest climate stations 
throughout Bavaria. Up to now, their time series are too short (from 3 to 5 years) to be used in long-term studies. Another problem is that the network is not dense (average distance is $90 \mathrm{~km}$ ). Therefore, for the reconstruction of long-term climatological data in the forest regions of Bavaria the climatological data set of the German weather service network is standard data source. Thus the purpose of this study is to develop a suitable method to interpolate the climatological data at weather stations to any forest site. Empirical transfer functions between observed and interpolated climatological data are then used to reconstruct the monthly mean forest climatological data for the last 30 years. This is a much more usable data base (Tabony, 1983) than the 3-5 years for which actual measurement data are available at present.

In a companion paper (Xia et al., 1999), we used a regression technique to fill gaps in the measurement time series. Thus, for this paper we have continuous time-series available during the 3-5 years of operation of the forest climate stations.

\section{Data and methods}

\subsection{Data}

The data used in this study are almost same as described in our companion paper (Xia et al., 1999). Therefore, we give a brief description only. Fourteen weather stations (Attenkam, Ebersberg, Holzkirchen, Leiblfing, Mainburg, Maisach-Gernlinden, Neutraubling, Oberschleissheim, Pfofeld-Langlau, Raisting, Saldenburg-Entschenreuth, Simbach, TraunsteinAxdorf) were removed from Table 1 of our companion paper because of short observational records
(5-20 years) for the period from 1965 to 1995 . Twenty-seven weather stations with complete observational records for this period and five weather stations with less than 4 years missing data were used. The five weather stations include Karlshuld, Pommelsbrunn and Wasserburg in Table 1 of our companion paper, and Muenchen-Riem $(527 \mathrm{~m}$ a.m.s.l., $48.13^{\circ} \mathrm{N}, 11.72^{\circ} \mathrm{E}$ ) and Kumhausen (436 m a.m.s.l., $\left.48.52^{\circ}, 12.15^{\circ} \mathrm{E}\right)$. Missing data at the five weather stations were filled using data from 27 weather stations and a multiple regression method (Xia et al., 1999). Therefore, 32 weather stations were used to reconstruct monthly forest climatological data at eight Bavarian forest sites.

Some 10-15\% of the forest climatological data were missing. These missing data were filled in using data from 27 weather stations and the multiple regression method described in Xia et al. (1999). For monthly precipitation $(\mathrm{P})$, the logarithmic transformation $\ln (0.1+\mathrm{P})$ was used. Eight forest climate stations located in stands of different tree species (i.e. beech, oak, pine, spruce) are listed in Table 1 (Preuhsler et al., 1995).

\subsection{Spatial interpolation of data}

Our method consists of two steps: First, the data from the weather stations were interpolated to the locations of the forest climate stations (Barnes, 1973). Second, a univariate regression method (Kemp et al., 1983; Kim et al., 1984; Wigley et al., 1990) was applied to derive the empirical transfer functions between observed and interpolated forest climatological data. Because of the shortness of the time series, a normalisation method (Huang, 1990) was used to reduce random effects.

Table 1

Eight forest climate stations of forest ecosystem monitoring network

\begin{tabular}{lllllll}
\hline Station name & Latitude $\left({ }^{\circ} \mathrm{N}\right)$ & Longitude $\left({ }^{\circ} \mathrm{E}\right)$ & Elevation $(\mathrm{m})$ & Start month year & End month year & Tree species \\
\hline Altdorf (ALT) & 49.42 & 11.32 & 406 & January 1991 & December 1995 & Pine \\
Altoetting (AOE) & 48.22 & 12.75 & 415 & October 1991 & December 1995 & Spruce \\
Ebersberg (EBE) & 48.12 & 11.92 & 540 & March 1991 & December 1995 & Spruce \\
Freising (FRE) & 48.40 & 11.65 & 508 & July 1994 & December 1995 & Beech \\
Landau (LAN) & 48.70 & 12.73 & 335 & October 1991 & December 1995 & Oak \\
Mitterfels (MIT) & 48.98 & 12.88 & 1025 & April 1991 & December 1995 & Beech \\
Riedenburg (RIE) & 48.93 & 11.77 & 475 & February 1991 & December 1995 & Oak \\
Schongau (SOG) & 47.88 & 10.80 & 780 & August 1992 & December 1995 & Beech \\
\hline
\end{tabular}


Since the reconstructed climatological data are to be available for any forest site in Bavaria, a $2 \mathrm{~km} \times 2 \mathrm{~km}$ grid was superimposed over the area of investigation. With the Barnes (1973) method, an estimated field of interpolated values is then computed at the grid points from the weighted sum of observations at the weather stations. The weighting function $\left(W_{i}\right)$ depends upon the distance $\left(D_{\text {in }}\right)$ between the observational station $(n)$ and grid point $(i)$ and is given by

$$
W_{i}=e^{\frac{-10 D_{\text {in }}^{2}}{D^{2}}}
$$

where $D$ is the radius of influence $(100 \mathrm{~km})$. Only stations within $D$ are used. Once an interpolated field is calculated as a first guess, estimated values are computed at the locations of the observing sites, using a 4-point average. Then the distance weighting function is used to interpolate the difference between these values and the true station data. From this, an interpolated difference field is formed, which is added to the guess field to provide a new field of interpolated values. A new difference field can be computed again, followed by the computation of another field of interpolated values. This process is iterated four times, which is sufficient to achieve convergence.

For the plain and valley forest climate stations, a simple Barnes interpolation was used. For hill and mountain forest climate stations, a topographically aided Barnes interpolation was used for temperature data (Xia and Winterhalter, 1998). The topographically aided Barnes interpolation differs from simple Barnes interpolation by using digital topographical model and lapse rates determined from the climatological data (1965-1995) to correct temperatures according to differences in station altitude.

\subsection{Empirical transfer functions}

A univariate regression analysis (Kemp et al., 1983; Kim et al., 1984; Wigley et al., 1990) was used between observed climatological data and estimated climatological data which were normalised by a variance method for every month (Huang, 1990). It is defined as follows:

$$
X_{\mathrm{F}}=a+b X_{\mathrm{W}}
$$

where $a$ and $b$ are the regression coefficients, $X_{\mathrm{F}}$ is the measured climatological parameter at a site, and $X_{\mathrm{W}}$ is the climatological parameter interpolated from the weather stations to this site. These regression equations were called empirical transfer functions.

Due to the use of a normalisation method for each month, 12 regression equations result when the normalised data are transferred to original climatological data, that is, each month has a regression equation for a variable at a forest site. These empirical transfer functions are used for reconstructing 31 years of forest climatological data.

\subsection{Method of discussing stability}

The stability of the regression equations was investigated by applying a Jack-knife method (Harnack and Lanzante, 1985). Two data sets for 5 (1991$1995)$ and 4 years (1992-1995) were used to calibrate the regression equations. The change of the variances explained by the different regression equations was examined for each climatological element. If the change is small, the regression equation is stable; if the change is large, the equation is not stable. The change $(C)$ was defined as

$$
C=\frac{\left|R_{4}^{2}-R_{5}^{2}\right|}{R_{5}^{2}}
$$

where $R_{4}^{2}$ and $R_{5}^{2}$ are the explained variances for the 4and 5-year data bases, respectively. We applied a $10 \%$ limit value for $C$.

\subsection{Quality control method}

A quality control method (Meek and Hatfield, 1994; Degaetano et al., 1995) was used to ensure the quality of monthly mean forest climate data. The control process assures that air temperatures satisfy $T_{\min }<T_{\mathrm{m}}$ $<T_{\max }$, and relative humidity is smaller than $100 \%$.

\subsection{Assessment criteria}

In order to evaluate the importance of the empirical transfer functions, mean absolute error (MAE) was used as an assessment criterion (Hulme et al., 1995; Xia et al., 1999). MAE provides a measure of how far the estimate can be in error, ignoring sign.

In general, a 30-year time series is considered to represent climate of a region (Tabony, 1983). Therefore, 31 year (1965-1995) data base was used to 
compare forest microclimate and surrounding mesoclimate. The differences of the data estimated with and without empirical transfer functions were used to represent the difference of both climates. The difference is represented as

$$
\Delta X=X_{\mathrm{F}}-X_{\mathrm{w}}
$$

where $X_{\mathrm{F}}$ is the climate element estimated by the empirical transfer functions and $X_{\mathrm{W}}$ is the climate element estimated by Barnes interpolation method alone, without correction by empirical transfer functions.

\section{Results and discussion}

The explained variances of empirical transfer functions are large, usually higher than $80 \%$ for air temperatures and water vapour pressure at most forest sites. They are significant at the 5\% level for all the six climatological variables and the eight forest sites (Table 2). Thus, these empirical transfer functions can be used with confidence.

\subsection{Importance of empirical transfer functions}

The mean absolute errors between observed and estimated (with empirical transfer functions) climatological data were much smaller than those between observed and estimated (without empirical transfer functions) climatological data for all the eight forest climate stations (Fig. 1). When the empirical transfer functions were used, mean absolute errors, averaged over all eight stations, were reduced by $90 \%$ for wind speed, more than $80 \%$ for daily minimum temperature, $40-60 \%$ for water vapour pressure, $60-70 \%$ for surface air temperature, and $40 \%$ for daily maximum temperature and precipitation amount.
The reduction of mean absolute errors was significant for all parameters at seven of the eight forest climate stations, except for station MIT (Fig. 1). As this station is located on a mountain ridge, topography is important. A topographically aided Barnes interpolation gives improved results over normal interpolation, but still cannot fully account for the role of topography.

The accuracy of the method varied from site to site. In general, the accuracies for each parameter were better at plain and valley forest climate stations than at mountain sites. For daily maximum temperature, daily minimum temperature and surface air temperature, the mean absolute error is smaller than $0.5^{\circ} \mathrm{C}$ at all forest climate stations except MIT. For water vapour pressure, MAE is less than $0.5 \mathrm{hPa}$ at all the eight forest climate stations and for wind speed MAE is smaller than $0.3 \mathrm{~m} / \mathrm{s}$ at all the eight forest climate stations. For precipitation amount, the accurate estimates can be given as $\ln (0.1+P)<0.3$. Here 0.1 has been added to $P$ to eliminate the problem with calculating the logarithm of zero. These results indicate that the empirical transfer functions improve estimates of the monthly mean forest climatological data in the forest regions, and enable the reconstruction of long-time forest climatological data, especially for wind speed, daily minimum temperature, mean air temperature and water vapour pressure.

\subsection{Stability of the empirical transfer functions}

Explained variances in Table 3 were used to calculate $\mathrm{C}$ values using Eq. (3) for the forest climate station EBE and RIE. $C$ is larger than $10 \%$ for monthly precipitation, but smaller than $10 \%$ for all other parameters. Thus, the empirical transfer functions are stable for all parameters but precipitation. For

Table 2

Determination coefficients $\left(R^{2}\right)$ of empirical transfer functions for maximum temperature $T_{\max }$, minimum temperature $T_{\min }$, mean air temperature $T_{\mathrm{m}}$, water vapour pressure $e$, wind speed $u$ and precipitation $P$ at eight forest sites

\begin{tabular}{|c|c|c|c|c|c|c|c|c|}
\hline Variable & Altdorf & Altoetting & Ebersberg & Feising & Landau & Mitterfels & Riedenburg & Schongau \\
\hline$T_{\max }$ & 0.730 & 0.962 & 0.890 & 0.998 & 0.981 & 0.560 & 0.933 & 0.984 \\
\hline$T_{\min }$ & 0.936 & 0.796 & 0.878 & 0.997 & 0.973 & 0.470 & 0.861 & 0.955 \\
\hline$T_{\mathrm{m}}$ & 0.864 & 0.946 & 0.879 & 0.988 & 0.976 & 0.780 & 0.942 & 0.976 \\
\hline$e$ & 0.862 & 0.857 & 0.880 & 0.998 & 0.820 & 0.500 & 0.614 & 0.904 \\
\hline$u$ & 0.630 & 0.543 & 0.410 & 0.596 & 0.401 & 0.190 & 0.280 & 0.318 \\
\hline $\ln (0.1+P)$ & 0.768 & 0.550 & 0.660 & 0.686 & 0.821 & 0.610 & 0.480 & 0.537 \\
\hline
\end{tabular}



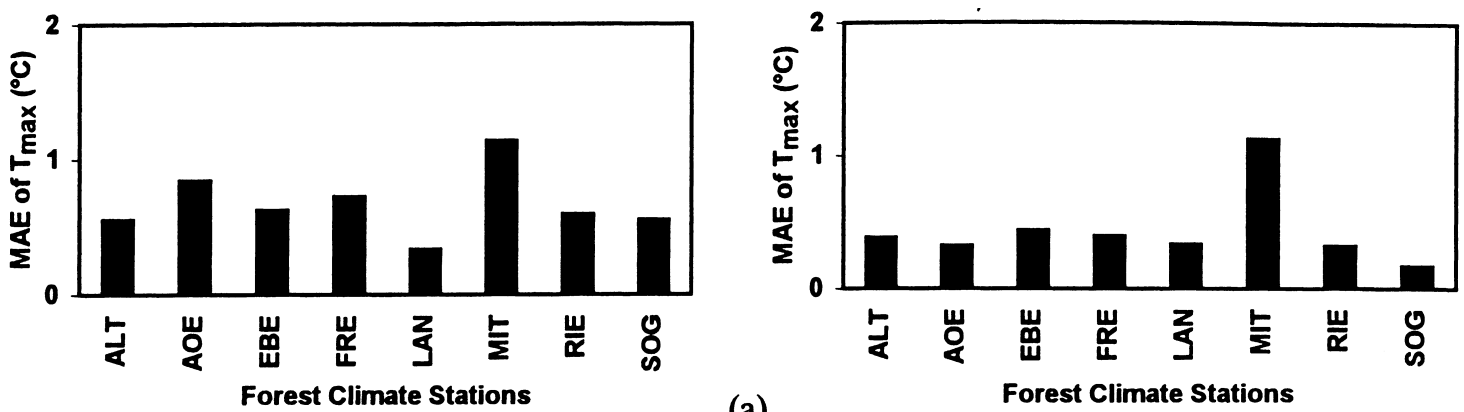

(a)
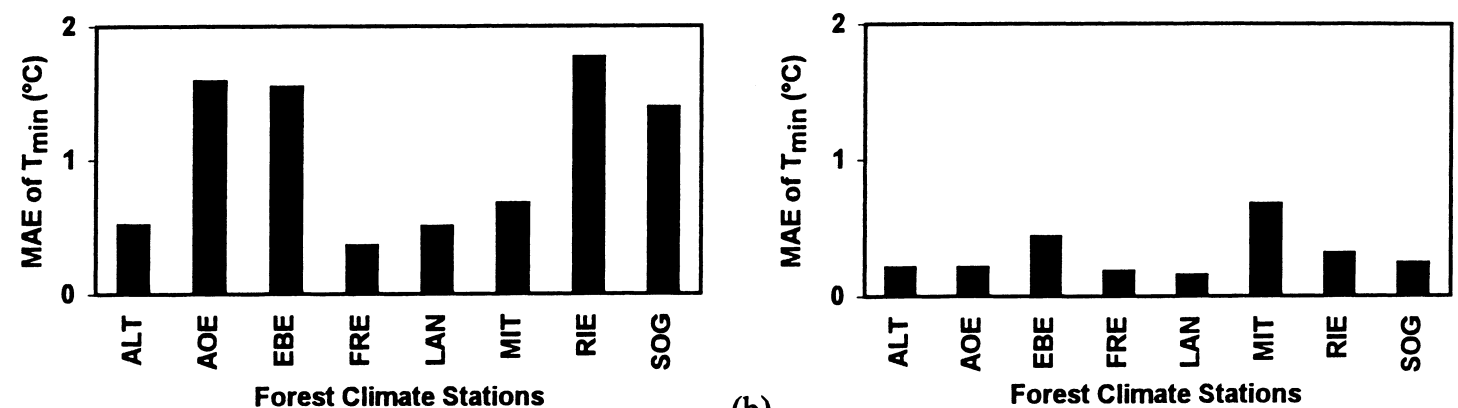

(b)
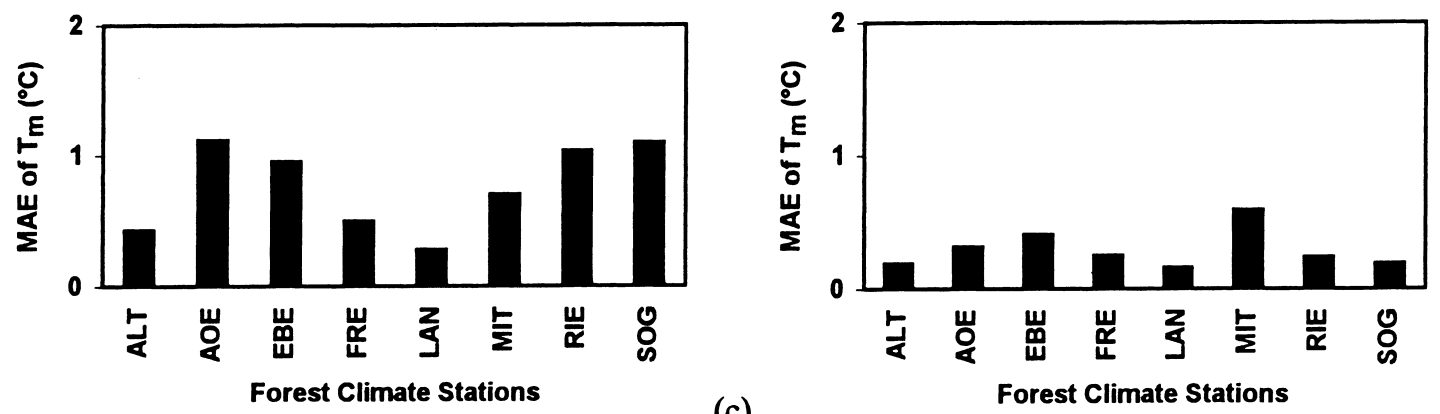

Fig. 1. Mean absolute errors, MAE, between observed and estimated (a) maximum temperature $T_{\max }$, (b) minimum temperature $T_{\min }$, (c) mean air temperature $T_{\mathrm{m}}$, (d) water vapour pressure $e$, (e) wind speed $u$ and (f) precipitation $P$ at eight forest climate stations (left: without empirical transfer functions, right: with empirical transfer functions, ALT $=$ Altdorf, AOE $=$ Altoetting, EBE $=$ Ebersberg, FRE $=$ Freising, LAN $=$ Landau, MIT $=$ Mitterfels, RIE $=$ Riedenburg, SOG $=$ Schongau $).$

the other forest climate stations, similar results were found (not shown).

\subsection{Reconstruction of 31-year forest climatological data}

Barnes interpolation and the empirical transfer functions at eight forest climate stations were used to reconstruct 31 years (1965-1995) of forest climate data in seven large forest regions of Bavaria. We exclude forest climate station FRE because of only 16 months of observations. They were not used for monthly precipitation because of detected instabilities. A final quality control (Meek and Hatfield, 1994; Degaetano et al., 1995) was used to ensure high quality forest climatological data, that is, monthly mean daily maximum temperature $\left(T_{\max }\right)$, minimum temperature $\left(T_{\min }\right)$ and mean air temperature $\left(T_{\mathrm{m}}\right)$ 

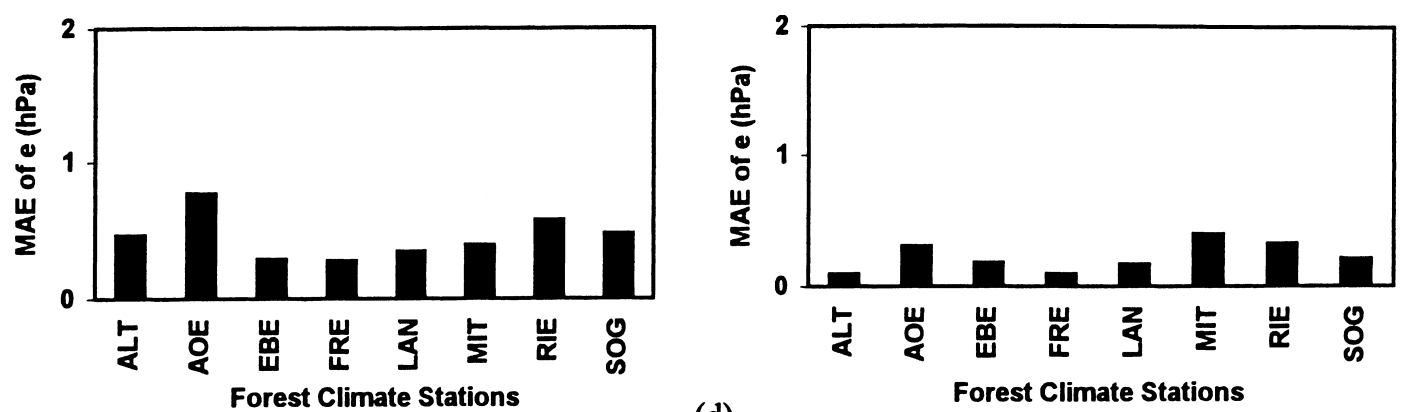

(d)
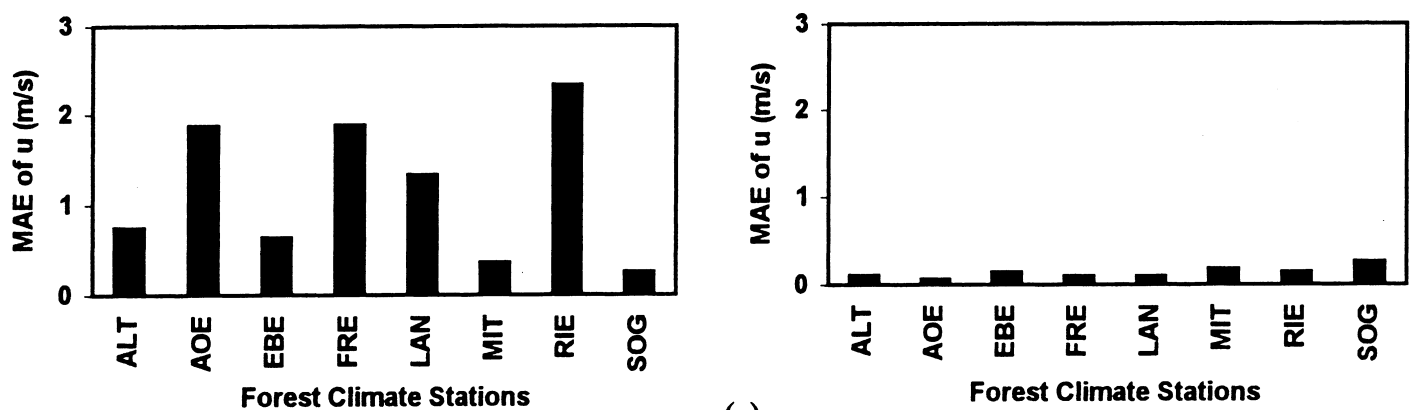

(e)
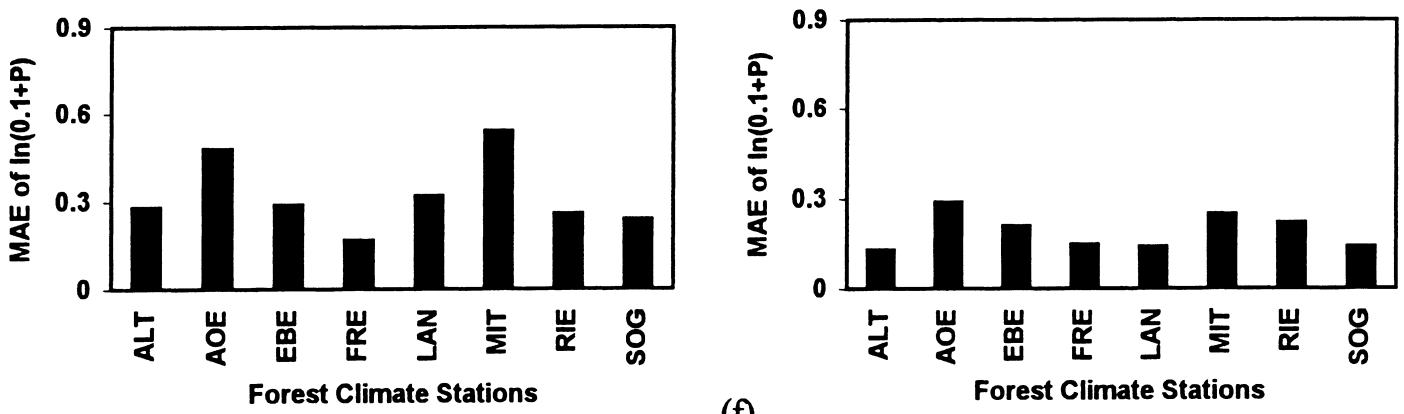

Fig. 1 (Continued).

Table 3

The explained variances $\left(R^{2}\right)$ of the regression equations for maximum temperature $T_{\max }$, minimum temperature $T_{\min }$, mean air temperature $T_{\mathrm{m}}$, water vapour pressure e, wind speed $\mathrm{u}$ and precipitation $P$ at forest climate station Ebersberg and Riedenburg

\begin{tabular}{|c|c|c|c|c|}
\hline \multirow[t]{2}{*}{ Meteorological Data } & \multicolumn{2}{|c|}{ Ebersberg } & \multicolumn{2}{|c|}{ Riedenburg } \\
\hline & 5 years & 4 years & 5 years & 4 years \\
\hline$T_{\max }$ & 0.89 & 0.88 & 0.93 & 0.89 \\
\hline$T_{\min }$ & 0.88 & 0.87 & 0.86 & 0.87 \\
\hline$T_{\mathrm{m}}$ & 0.88 & 0.89 & 0.94 & 0.95 \\
\hline$e$ & 0.88 & 0.89 & 0.61 & 0.60 \\
\hline$u$ & 0.41 & 0.45 & 0.28 & 0.30 \\
\hline $\ln (0.1+P)$ & 0.66 & 0.74 & 0.48 & 0.58 \\
\hline
\end{tabular}



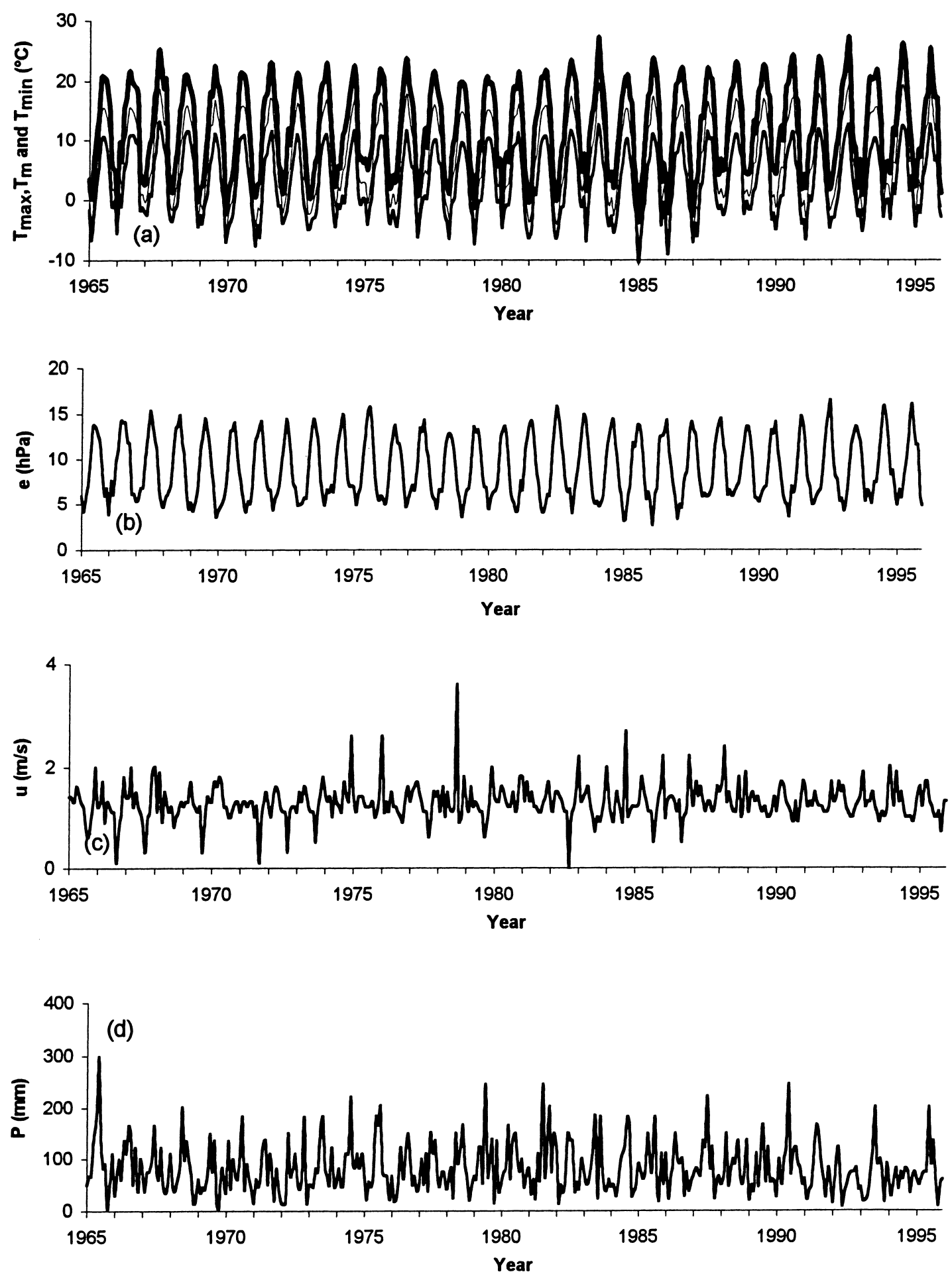

Fig. 2. Reconstructed (a) maximum temperature $T_{\max }$, minimum temperature $T_{\min }$ and mean air temperature $T_{\mathrm{m}}$, (b) water vapour pressure $e$, (c) wind speed $u$ and (d) precipitation $P$ in the forest region Ebersberg. 
must satisfy $T_{\min }<T_{\mathrm{m}}<T_{\max }$. Water vapour pressure must satisfy RH $\left(T_{\mathrm{m}}, \mathrm{e}\right) \leq 100 \%$. Certainly wind speed and precipitation must be larger than or equal to 0.0 . If $U$ or $P<0.0$, negative values were replaced by zero. If $\mathrm{RH}\left(T_{\mathrm{m}}, \mathrm{e}\right)>1.0, e$ was calculated using $T_{\mathrm{m}}$ and $\mathrm{RH}$ $(\mathrm{RH}=1.0)$. If $T_{\max }, T_{\mathrm{m}}$ and $T_{\min }$ do not satisfy $T_{\min }<T_{\mathrm{m}}<T_{\max }$, a manual correction method was used (Degaetano et al., 1995). The reconstructed 31-year monthly mean forest climatological data at the station EBE are shown in Fig. 2. These reconstructed forest climatological data show evident interannual and seasonal variations. The warmest years were 1967, 1983, 1992 and 1994, and the coldest years were 1965 and 1985 (Fig. 2(a)). The driest year was 1992 and the wettest year was 1965 (Fig. 2(d)). The strongest average wind occurred in 1988 (Fig. 2(c)). These results are in agreement with the climate observations from the German weather service.

\subsection{Comparison of forest microclimate and surrounding mesoclimate}

In order to use the reconstructed forest climate data in the best possible way, a comparison of the forest microclimate and the mesoclimate in the surroundings is needed. The forest microclimate is represented by the reconstructed forest climate data, the surrounding mesoclimate is represented by climatological data interpolated from the German weather stations.

\subsubsection{Air temperature}

Monthly mean air temperatures at six forest climate stations (Table 2) were significantly lower (at the $95 \%$ confidence level) in the period 1965-1995 when compared to the surrounding environment (Fig. 3), especially during the growing season (April-October). In winter (November-March), monthly mean air temperatures at six forest climate stations were similar when compared to the surrounding environments. The annual mean differences of monthly mean surface air temperatures between forest and surrounding environments were $-0.4^{\circ} \mathrm{C}$ at $\mathrm{ALT},-1.0^{\circ} \mathrm{C}$ at $\mathrm{AOE}$, $-1.0^{\circ} \mathrm{C}$ at EBE, $-0.2^{\circ} \mathrm{C}$ at $\mathrm{LAN},-1.0^{\circ} \mathrm{C}$ at $\mathrm{RIE}$ and $-1.0^{\circ} \mathrm{C}$ at $\mathrm{SOG}$, respectively. This shows that the forest has a cooling effect, as is expected. The seasonal variation is also as expected, that is, the differences for the growing season were larger than in winter.
Mean monthly maximum and minimum air temperatures were significantly higher (at the $95 \%$ confidence level) in the surrounding environments than in forests, too (Fig. 3). In general, the differences of minimum temperatures between surrounding and forest environments were much larger than those of overall air temperatures. Differences of minimum temperatures between surrounding and forest environments were largest in May $\left(1-3.5^{\circ} \mathrm{C}\right)$ when the vegetation is most active and smallest in winter $\left(-1.0\right.$ to $\left.-1.2^{\circ} \mathrm{C}\right)$, at all the forest climate stations.

Differences in the microclimates between the surrounding and the forest climate strongly relate to the modification of the environmental parameters by forest structure. The interception of solar energy regulated by the phenological status of the forest canopy results in lower surface air temperature at forest climate stations than in the surrounding environments. These results are in good agreement with those from Geiger (1965) and Johnson et al. (1977), although the differences of surface air temperatures were smaller than those of Johnson et al. (1977). This is plausible because our forest climate stations are located in forest clearances (mainly forest meadows) with a diameter of at least four times the height of old trees, and Johnson's forest climate stations were located directly in forest stands. In addition, Johnson used two urban weather stations, whereas our stations have mostly rural or suburban character.

Usually the differences of monthly mean minimum temperatures and air temperatures found between surrounding and forest environments were larger at the stations located in a valley or on a mountain than at stations in the plains (Fig. 3). Maybe this is a result of the non-linear interaction between forest and topography.

\subsubsection{Water vapour pressure}

Monthly mean relative humidity found to be $3-5 \%$ higher in forest environments than in the background during the growing season, whereas monthly mean water vapour pressures were smaller at all forest climate stations than in the corresponding surrounding environments. This is a result of lower temperatures in the forests. The seasonal variation of differences of monthly mean water vapour pressures between forest and surrounding environments was evident, too (Fig. 4). Generally speaking, during the growing sea- 

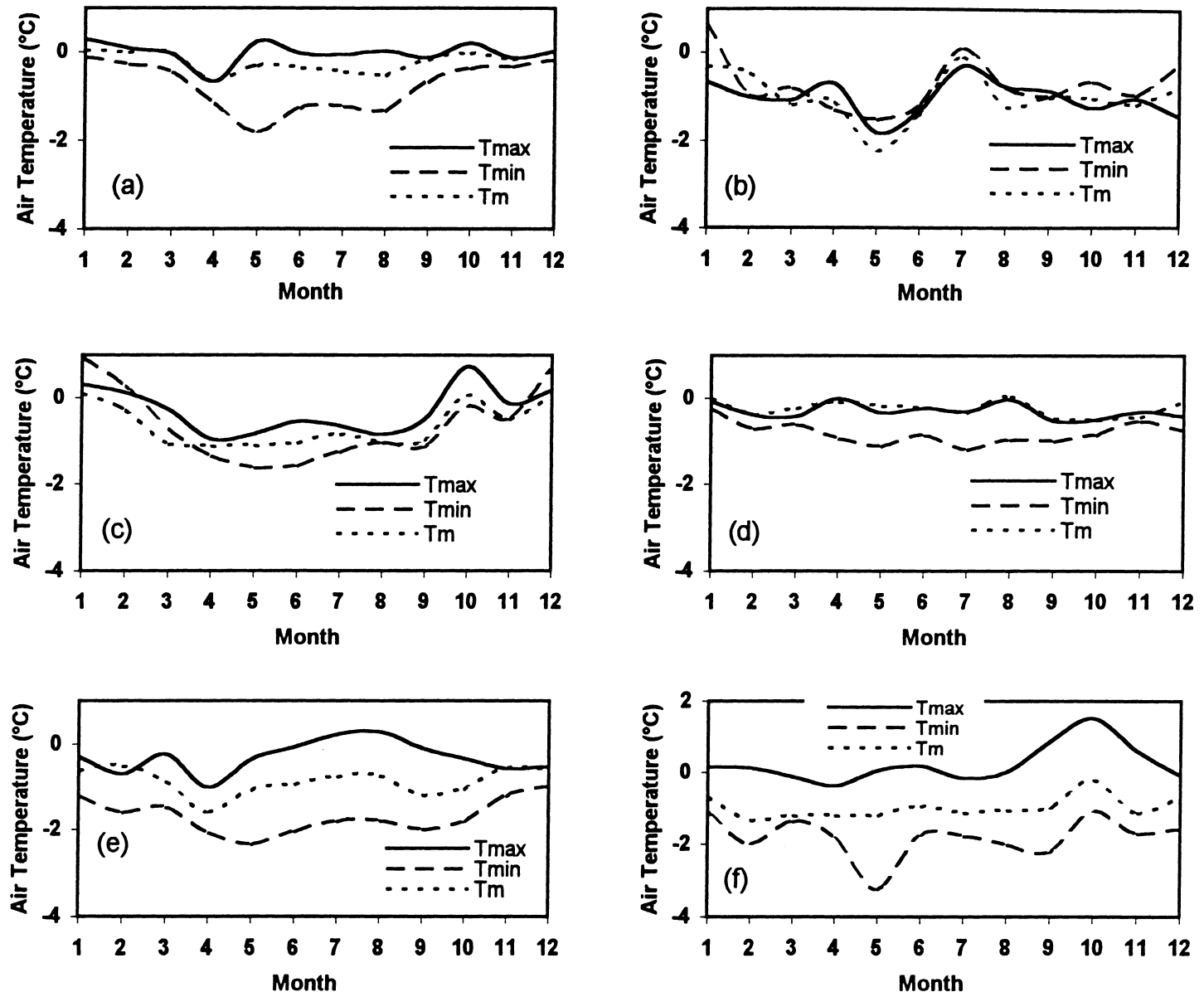

Fig. 3. Thirty-one-year averaged values of difference $(\Delta X)$ for maximum temperature $T_{\max }$, minimum temperature $T_{\min }$ and mean air temperature $T_{\mathrm{m}}$ at forest climate stations (a) Altdorf, (b) Altoetting (c) Ebersberg, (d) Landau, (e) Riedenburg and (f) Schongau.
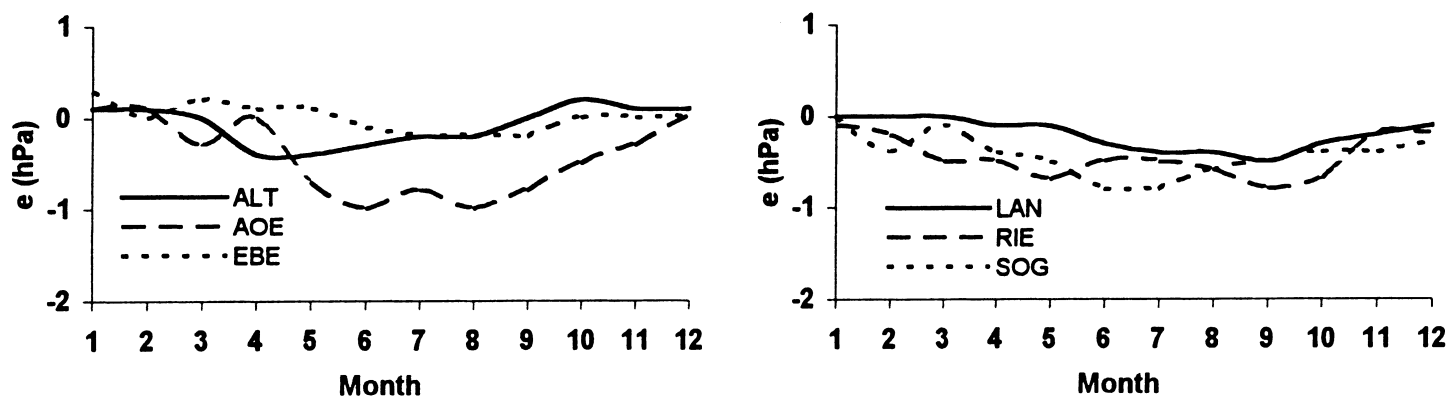

Fig. 4. Thirty-one-year averaged values of difference $(\Delta X)$ for water vapour pressure e for six forest climate stations (ALT $=$ Altdorf, $\mathrm{AOE}=$ Altoetting, $\mathrm{EBE}=$ Ebersberg, $\mathrm{LAN}=$ Landau, $\mathrm{RIE}=$ Riedenburg, $\mathrm{SOG}=$ Schongau $)$. 

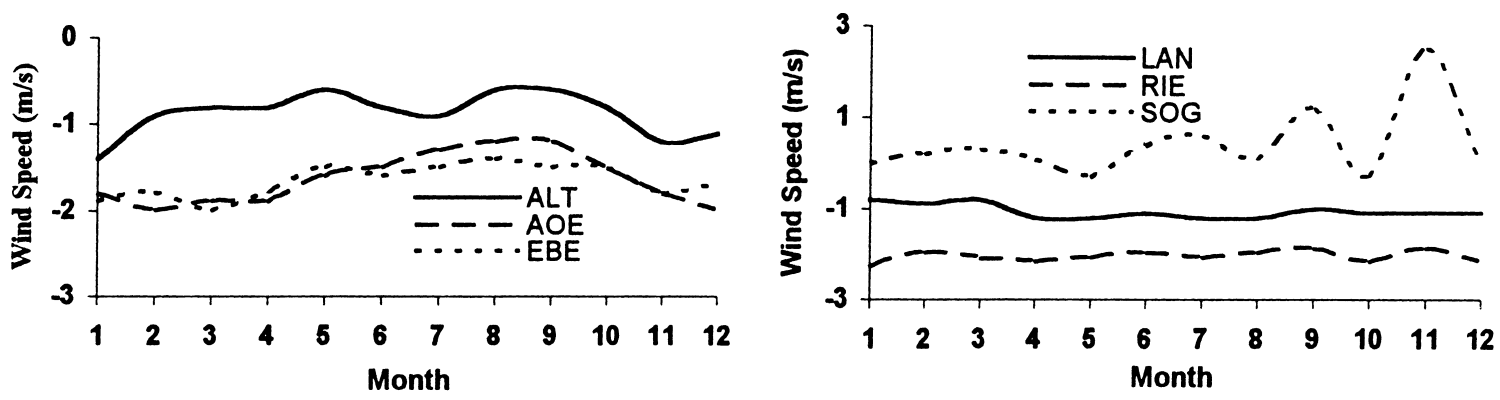

Fig. 5. Thirty-one-year averaged values of difference $(\Delta X)$ for wind speed for six forest stations (ALT $=$ Altdorf, AOE $=$ Altoetting, $\mathrm{EBE}=$ Ebersberg, $\mathrm{LAN}=$ Landau, RIE $=$ Riedenburg, $\mathrm{SOG}=$ Schongau $).$

son (April-October) differences of monthly mean water vapour pressures between forest and surrounding environments were -0.5 to $-1.0 \mathrm{hPa}$, whereas in winter (November-March) they were smaller than $0.5 \mathrm{hPa}$. This means that water vapour pressure within the forest clearances is slightly lower, whereas relative humidity is a little higher than outside the forest regions.

\subsubsection{Wind speed}

The differences of monthly mean wind speeds between the forest and surrounding environments was large and showed little seasonal variation (Fig. 5). The difference is $1-2 \mathrm{~m} / \mathrm{s}$ at the forest climate stations except for the forest climate station SOG where the wind speed in the forest is slightly higher than outside. SOG is located on a hill (about $800 \mathrm{~m}$ ), and the surrounding weather stations are located in plain areas (300-400 m). The topographic effect opposes that of the forest, producing this small increase in wind speed. However, data of the other stations clearly show that wind speeds inside the forest clearances are usually $1-2 \mathrm{~m} / \mathrm{s}$ smaller than outside the forest area.

\subsection{Comparisons of forest climates in three typical forest regions}

In order to use the reconstructed forest climate data, climates of three forest regions are compared. At many stations, forest climates were represented by the interpolated data from weather stations. The above results show that this is not accurate, because mean absolute errors for monthly mean minimum temperature and air temperature $\left(1-2^{\circ} \mathrm{C}\right)$, for wind speed $(1-2 \mathrm{~m} / \mathrm{s})$ and for the water vapour pressure $(0.5-1.0 \mathrm{~h} \mathrm{~Pa})$ are large during the growing season. These errors are significant at the $95 \%$ confidence level. Therefore, using empirical transfer functions can give more accurate estimates. Forest climate in forest region RIE (Danube valley), forest region EBE (foothills of the Alps) and forest region MIT (near mountain Grosser Arber) are shown in Fig. 6. The monthly mean maximum temperature, air temperature and water vapour pressure typically decrease with increasing elevation (Fig. 6 $(a, c, d))$. However, the variation of monthly mean minimum temperature with elevation was small (Fig. 6(b)). Monthly mean wind speed and monthly precipitation typically increased as elevation increased (Fig. 6(e,f)), although the estimated monthly precipitation at MIT was smaller than the observed one. In the winter half year (October-March) air temperature (maximum temperature, minimum temperature) in the valley was smaller than that in the plain. These results are relatively consistent with the earlier observations (Geiger, 1965; Bolstad et al., 1998).

From the valley to the foothills of the Alps, monthly precipitation increased with elevation. In June it increased from $90 \mathrm{~mm}$ in the valley to $135 \mathrm{~mm}$, in December it increased by less than $10 \mathrm{~mm}$ from the valley to the foothills of the Alps.

\section{Conclusions}

Our analysis applied to eight forest climate stations in Bavaria showed that empirical transfer functions were important to estimate climatological data for 

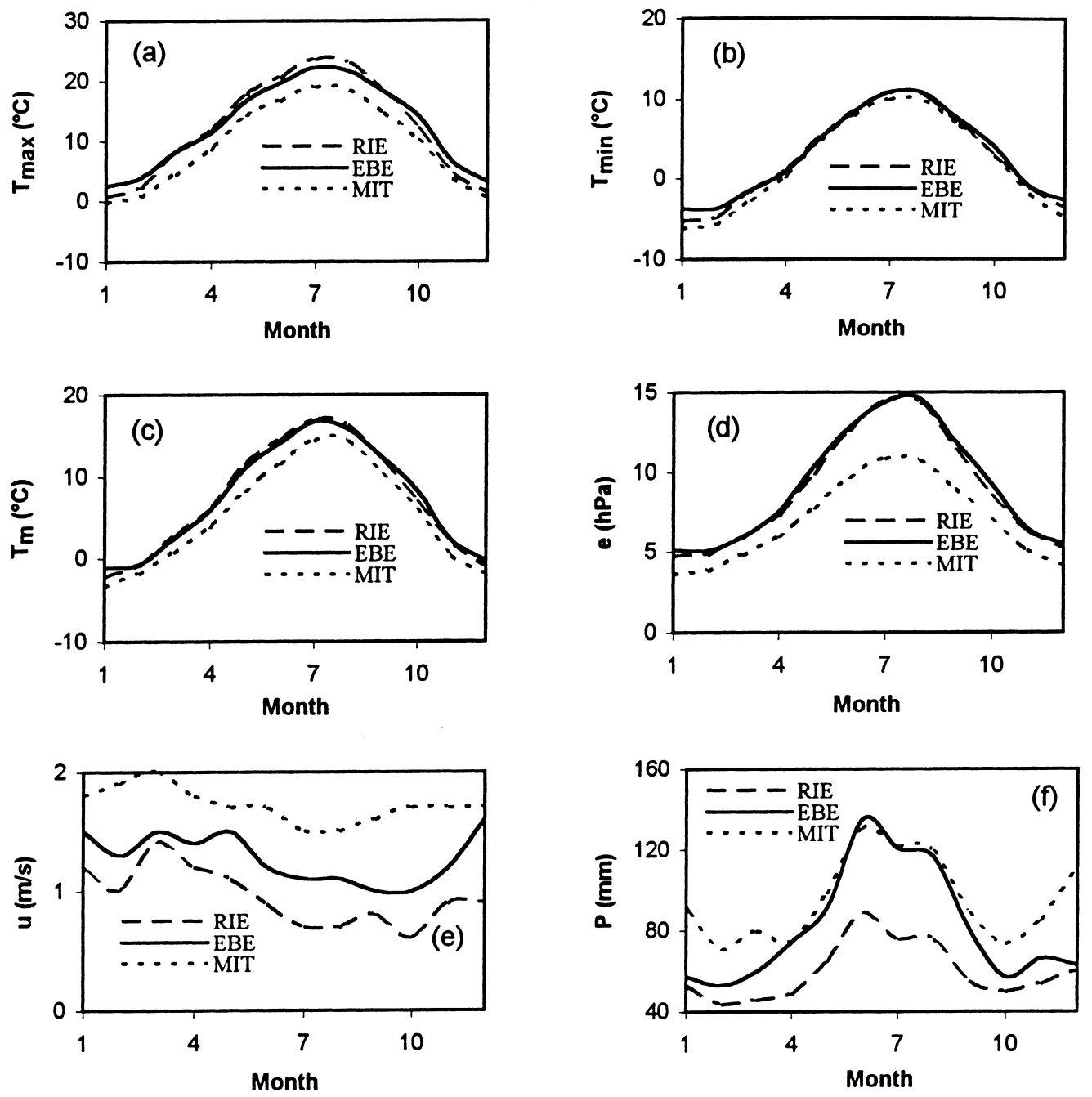

Fig. 6. Thirty-one-year (1965-1995) averaged (a) maximum temperature $T_{\max }$, (b) minimum temperature $T_{\min }$, (c) mean air temperature $T_{\mathrm{m}}$, (d) water vapour pressure e, (e) wind speed $u$ and (f) precipitation $\mathrm{P}$ for three forest climate regions $(\mathrm{EBE}=\mathrm{Ebersberg}$, MIT $=$ Mitterfels, RIE $=$ Riedenburg).

forest areas. In general, they reduced the MAE by more than $90 \%$ for monthly mean wind speed, more than $80 \%$ for monthly mean minimum temperature, about $70 \%$ for monthly mean air temperature and about $40-60 \%$ for monthly mean maximum temperature, monthly mean water vapour pressure and monthly precipitation at the plain and valley forest climate stations. At the mountain forest climate stations the effect of topography on monthly mean climatological data was much more important than that of the forest.
Thirty-one-year monthly mean forest climatological data were reconstructed by Barnes interpolation and the empirical transfer functions. The reconstructed climatological data at station EBE clearly showed the interannual and seasonal variation. The comparison of the forest microclimate and surrounding mesoclimate was made by the reconstructed forest climate data at six forest climate stations. The results showed that during the growing season monthly mean minimum temperature (air temperature) inside forest regions is $1.0^{\circ} \mathrm{C}-2.5^{\circ} \mathrm{C}$ lower than outside. Monthly 
mean water vapour pressure inside the forest regions was $0.5-1.0 \mathrm{hPa}$ smaller than outside, and monthly mean wind speed inside the forest regions was $1-2 \mathrm{~m} / \mathrm{s}$ smaller than outside. The difference of monthly mean maximum temperatures between forest and surrounding environments was small. Due to the instabilities of empirical transfer functions for monthly precipitation, the difference of monthly precipitation amounts between the forest and surrounding environments was not discussed.

Comparisons made here indicate that most of the differences between surrounding climates and forest microclimates are a result of the structural characteristics of the forest vegetation and their effects on radiation interception and reduction of wind speed. In addition, the particular locations of the forest climate stations (i.e. valley, hill top, mountain), were found to be important for the modification of the forest microclimates. By using surrounding weather station data or data interpolated from these weather stations by various interpolation techniques, to describe the physical environment of forested ecosystems, where direct measurements are not available, the substitution should only be made with the realisation that compensations should be made for the differences in the two environments. Our analysis results showed that data directly interpolated from weather stations to forest sites should be used with caution, because forest microclimates are different from the surrounding climates represented by weather station data.

\section{Acknowledgements}

We thank the Bavarian State Institute of Forestry and the German Weather Service for providing climate data. We wish to thank Dr. John Stewart and two anonymous referees whose comments greatly improved the quality of this paper. The work was partly funded by Bavarian Ministry of Food, Agriculture and Forestry as project no. M26.

\section{References}

Barnes, S.L., 1973. Mesoscale objective map analysis using weighting time-series observations. NOAA Tech. Memo. ERL NSSL-62. US Dept. of Commerce, p. 60.
Bolstad, P.V., Bentz, B.J., Logan, J.A., 1997. Modelling microhabitat temperature for dendroctonus ponderosae (coleoptera: scolytidae). Ecol. Model 94, 287-297.

Bolstad, P.V., Swift, L., Collins, F., Regniere, J., 1998. Measured and predicted air temperatures at basin to regional scales in the southern Appalachian mountains. Agric. For. Meteorol. 91, $161-176$.

Degaetano, A.T., Eggleston, K.L., Knapp, W.W., 1995. A method to estimate missing maximum and minimum temperature observations. J. Appl. Meteorol. 34, 371-380.

Geiger, R., 1965. The Climate Near the Ground. Harvard University, Cambridge, MA, p. 611.

Harnack, R.P., Lanzante, J.R., 1985. Specification of United States seasonal precipitation. Monthly Weather Rev. 113, 319-325.

Hendriks, K., Klap, J., Je Joung, E., Van Leeuwen, E., De Vries, W., 1997a. Calculation of natural stress factors. In: Ten Years of Monitoring Forest Condition in Europe, EC-UN/ECE, Brussels, Geneva, 225-240.

Hendriks, C.M.A., De Vries, W., Oude Voshaar, J.H., Van Leeuwen, E.P., Klap, J.M., 1997b. Assessment of the possibilities to derive relationships between stress factors and forest condition 2. Application for The Netherlands. DLO Winand Staring Centre for Intergrated Land, Soil and Water Research, Report, Winand, The Netherlands.

Huang, J.Y., 1990. Statistical Analysis and Forecasting Methods in Meteorology. Chinese Meteorological Publishing House, Beijing, p. 385.

Hulme, M., Conway, D., Jones, P.D., Jiang, T., Barrow, E.M., Turney, C., 1995. Construction of a 1961-1990 European climatology for climate change modelling and impact applications. Inter. J. Clim. 15, 1333-1363.

Johnson, F.L., Bell, D.T., Sipp, S.K., 1977. A comparison of urban and forest microclimates in the midwestern United States. Agric. Meteorol. 14, 335-345.

Kemp, W.P., Burnell, D.G., Everson, D.O., Thomson, A.J., 1983. Estimating missing daily maximum and minimum temperatures. J. Climate Appl. Meteorol. 22, 1587-1593.

Kim, J.W., Chang, J.T., Baker, N.L., Wilks, D.S., Gates, W.L., 1984. The statistical problem of climate inversion: Determination of the relationship between local and large-scale climate. Monthly Weather Rev. 112, 2069-2077.

Meek, D.W., Hatfield, J.L., 1994. Data quality checking for single station meteorological databases. Agric. For. Meteorol. 69, 85109.

Preuhsler, T., Adler J., Gietl, G., 1995. Bayerische Waldklimastationen Jahrbuch 1994. Bayerische Landesanstalt für Wald und Forstwirtschat, Sachgebiet Forsthydrologie. Freising, Germany.

Running, S., Nemani, R., Hungerford, R., 1987. Extrapolation of synoptic meteorological data in mountainous terrain and its use for simulating forest evapotranspiration and photosynthesis. Can. J. For. Res. 17, 472-483.

Russo, J.M., Liebhold, A.M., Kelley, J.G.W., 1993. Mesoscale weather data as input to a gypsy moth (Lepidoptera: Lymantriidae) phenology model. J. Econ. Entomol. 86, 838844. 
Tabony, R.C., 1983. The estimation of missing climatological data. J. Climatol. 3, 297-314.

Wigley, T.M.L., Jones, P.J., Briffa, K.R., Smith, G., 1990. Obtaining sub-grid-scale information from coarse-resolution general circulation model output. J. Geophys. Res. 95, 19431953.
Xia, Y., Winterhalter, M., 1998. A model to interpolate monthly mean climatological data at Bavarian forest climate stations. Theor. Appl. Climatol. (submitted).

Xia, Y., Fabian, P., Stohl, A., Winterhalter, M., 1999. Forest climatology: Estimation of missing values for Bavaria, Germany. Agric. For. Meteorol. (in press). 